\title{
The effects of the natural enzyme, Pectinex Ultra SP-L, on human cell cultures and bacterial biofilms in vitro
}

lan P Olwoch, Oppel B W Greeff, Gisela Jooné and Vanessa Steenkamp*

\begin{abstract}
Background: Pectinex Ultra SP-L (Pectinex) is a microbial-derived enzyme that is used in the food industry and that has been shown to inhibit bacterial biofilms. It has been suggested that Pectinex may be useful in the management of biofilm-related bacterial infections and therefore warrants further investigation in this regard. The aim of this study was to investigate the cytotoxicity of Pectinex on cervical adenocarcinoma cells (HeLa), lymphocytes and neutrophils. Cell viability and morphology were assessed using an in vitro spectrophotometric MTT (3-(4, 5-dimethylthiazol-2-yl)-2, 5-diphenyl tetrazolium bromide) assay and polarization-optical transmitted light differential interference contrast microscopy. This study also investigated the antibacterial and antibiofilm actions of Pectinex, alone and in combination with antibiotics, on standard and clinical cultures of Staphylococcus aureus and Pseudomonas aeruginosa. Minimum inhibitory (MIC) and bactericidal (MBC) concentrations were determined using $p$-iodo-nitrotetrazolium violet staining of bacterial cultures and regrowth of subcultures. Biofilm biomass and cell viability were quantified spectrophotometrically after staining with crystal violet and MTT.
\end{abstract}

Results: The $\mathrm{IC}_{50}( \pm$ SEM) of Pectinex was 193.9 ( \pm 22.2$)$ PGU/ml for HeLa cells, $383.4( \pm 81.5)$ and $629.6( \pm 62.8)$ PGU/ $\mathrm{ml}$ for fMLP-stimulated and non-stimulated lymphocytes respectively, and $245.9( \pm 9.4)$ and $529.7( \pm 40.7)$ PGU/ml for fMLP-stimulated and non-stimulated neutrophils, respectively. Induced morphological features characteristic of apoptosis and necrosis included cell membrane blebs and vacuolization in HeLa cells, clumping in lymphocytes, as well as shrunken rounded cells, apoptotic bodies and debris in all cultures. Pectinex $\left(7.42-950 \mathrm{PGU} / \mathrm{ml}^{-1}\right)$ was not bactericidal. In clinical cultures of Staphylococcus aureus, co-administration of Pectinex was associated with a $28.0 \%$ increase in both the MIC and MBC of amoxicillin-clavulanate. In clinical cultures of $P$. aeruginosa, there was an $89.0 \%$ and $92.8 \%$ increase in the MIC and MBC of ciprofloxacin, respectively. Pectinex $\leq 118.75 \mathrm{PGU} / \mathrm{ml}^{-1}$ and incubation periods $\geq 6 \mathrm{~h}$ were associated with increased biomass and cell viability in $S$. aureus or $P$. aeruginosa biofilms.

Conclusions: Pectinex appeared to antagonize the antibacterial effects of amoxicillin-clavulanate and ciprofloxacin and furthermore demonstrated significant cytotoxicity. It was therefore deemed unsuitable for the management of either planktonic or biofilm phenotypes of $S$. aureus or P. aeruginosa.

Keywords: Antibiotic, Biofilm, Cytotoxicity, Enzyme, HeLa cell, Lymphocyte, Neutrophil, Pectinex, Pseudomonas aeruginosa, Staphylococcus aureus

\footnotetext{
* Correspondence: vanessa.steenkamp@up.ac.za

Department of Pharmacology, Faculty of Health Sciences, University of

Pretoria, Private Bag X323, Arcadia, 0007 Pretoria, South Africa
} 


\section{Background}

The alarming worldwide increase in the incidence of bacterial resistance to antimicrobial agents has prompted the urgent need for the development of new drugs and treatment strategies [1-3]. In addressing this problem, scientists acknowledge that bacteria naturally occur as integrated surface bound communities; the biofilm. Bacterial biofilms are dynamic, integrated, heterogeneous (spatial, genetic and physiologic) cell communities, encased in a complex extracellular matrix, that are either surface-bound or free-floating in cohesive cell-tocell clusters $[4,5]$. In the biofilm-state, bacteria are more resistant to antibiotics, disinfectants and host immune mechanisms than their planktonic phenotype [6]. However, when dispersed from the biofilm, bacteria revert to the planktonic phenotype with rapid restoration of antibiotic sensitivity [4,7]. Several studies have demonstrated that natural enzymes obtained from animals, plants and microbes (bacteria and fungi), are able to prevent the formation and facilitate the removal of bacterial biofilms, and potentiate the action of co-administered antibiotics in vitro. Their actions are mediated through enzymatic degradation of the biofilm matrix. As a treatment strategy, biofilm matrix-degrading enzymes may offer a solution to the management of persistent biofilm-related infections when used either as the sole antimicrobial agents or as adjuncts to conventional antibiotic therapy [8].

Many natural enzymes are readily available and in everyday use as catalysts in numerous domestic and industrial applications, including production of food and beverages, paper, textiles, leather, cosmetics and pharmaceuticals $[8,9]$. Pectinex Ultra SP-L (Pectinex) is a fungal enzyme complex derived from Aspergillus aculeatus. The main enzyme in the preparation is polygalacturonase. It is used in the maceration of plant cells for the preparation of mash (puree) foods and the extraction of juices and oils from fruits, vegetables and grain [10]. Pectinex has neither bactericidal nor bacteriostatic activity. Yet, it is known to possess both protease and carbohydrase activity and has been shown to degrade the exopolymeric matrix of Staphylococcus aureus and Pseudomonas aeruginosa. This has led to the suggestion that the potential antibiofilm effect of Pectinex may be useful in the management of bacterial infections $[11,12]$.

Despite the availability of numerous commercial enzymes, very little about their in vitro toxicity is known [13]. In general, they are considered to be non-toxic. Industrial processes use enzymes at low levels after which they are either removed or deactivated from the final product, and the orally ingested residual amounts are likely to be digested and rendered harmless. However, they contain added substances such as preservatives and stabilizers which are a potential problem when enzymes are consumed in food and drink [14]. They may also contain toxins and other metabolites from their source microorganisms which may be harmful [15]. The potential for adverse and toxic effects is of concern to regulatory authorities who have recommended that no new enzyme should be introduced into the food and beverage industry, or that existing enzymes be adapted for new applications, without assessment of their safety [16]. Existing proprietary knowledge of Pectinex toxicity may not be applicable to its "off-label" use as an antimicrobial agent. To our knowledge, no toxicity testing of Pectinex has been performed. Therefore, formal investigation is required before this basic research can translate into clinical experimentation and use. Consideration should be given to the effective antimicrobial concentrations and the effect on the tissues that are exposed [17].

This study investigated the effect of Pectinex as a single agent and also when used in combination with amoxicillin-clavulanate and ciprofloxacin against $S$. aureus and $P$. aeruginosa, respectively. The effect of Pectinex on cervical adenocarcinoma cells, lymphocytes and neutrophils was investigated, as these cell types represent host cells that may be found at the site of an infection. This is the first study to report on the combined effect of antibiotics with Pectinex in bacterial biofilms and on the cytotoxicity of Pectinex in cell cultures.

\section{Methods}

\section{Test agents}

Pectinex (9500 polygalacturonase units per millilitre; PGU ml ${ }^{-1}$ ) was obtained from Novozymes (Pty) Ltd (Johannesburg, SA), amoxicillin-clavulanate from Sandoz (SA) and ciprofloxacin from Adcock Ingram (SA).

\section{Cell cultures and maintenance}

HeLa cells were obtained from the American Type Culture Collection (ATCC CCL-2). Cells were maintained in Eagle's minimal essential medium supplemented with $10 \%$ foetal bovine serum and $1 \%$ penicillin and streptomycin (EMEM+). Once adherent cells reached 70-80\% confluency, cells were detached with $0.25 \%$ trypsin/versene. The concentration of viable cells was determined by the trypan blue exclusion method [18].

Ethical approval to collect blood from healthy adult volunteers was obtained from the University of Pretoria Ethics Committee (26-08-2009). Written informed consent was obtained from the participants. Lymphocytes and neutrophils were isolated by continuous densitygradient centrifugation over Histopaque 1077 (SigmaAldrich, St Louis, Missouri, USA) using a method adapted from Pretlow and Luberoff [19]. Working 
suspensions of lymphocytes and neutrophils were made by dilution with Roswell Park Memorial Institute Medium (RPMI-1640; Sigma-Aldrich) supplemented with 10\% volume of autologous serum and $1 \%$ penicillin-streptomycin (RPMI+).

\section{Cytotoxicity microtitre challenge of cell cultures}

Round-bottomed 96-well microtitre plates (USA Scientific Inc., USA) were seeded with $100 \mu \mathrm{l}$ aliquots of cell suspension $\left(2.5 \times 10^{4}\right.$ cells $/ \mathrm{ml}$ for HeLa cells; $2 \times 10^{6}$ cells $/ \mathrm{ml}$ for lymphocytes and neutrophils). Wells which served as experiment blanks were devoid of cells and received $180 \mu \mathrm{l}$ of culture medium and $20 \mu \mathrm{l}$ of Pectinex $9500 \mathrm{PGU} / \mathrm{ml}$. The plates seeded with HeLa cells were incubated without Pectinex for 60 min to allow the cells to resume growth after a medium change. Wells that contained culture medium without Pectinex served as the negative control, whereas wells with Mitomycin C $(10 \mu \mathrm{g} / \mathrm{ml})$ were used as the positive control. Challenge wells received $20 \mu \mathrm{l}$ aliquots of serial dilutions of Pectinex $(7.42-950 \mathrm{PGU} / \mathrm{ml})$. The final volume in all the wells was titrated to $200 \mu \mathrm{l}$ with culture medium. Experiments were performed on resting lymphocytes and neutrophils and also after stimulation with $20 \mu \mathrm{l}$ of $0.2 \% \mathrm{w} / \mathrm{v} \mathrm{N}$-formylmethionyl-leucyl-phenylalanine (fMLP, Sigma-Aldrich, St Louis, Missouri, USA). fMLP is an agent that causes lymphocytes and neutrophils to become metabolically active and mimic their behaviour as it would be in the presence of bacteria. HeLa cells were incubated for 7 days, lymphocytes for 3 days and neutrophils for $4 \mathrm{~h}$.

\section{Viability assay of cell cultures}

Cell viability was determined using the MTT (3- $(4,5-$ dimethylthiazol-2-yl)-2, 5-diphenyl tetrazolium bromide) assay according to Grare et al. [20]. A $20 \mu \mathrm{l}$ aliquot of MTT $(1 \mathrm{mg} / \mathrm{ml})$ was added to the wells and the plate incubated for $4 \mathrm{~h}$. The plates were centrifuged at $650 \mathrm{~g}$ for $10 \mathrm{~min}$ after which the supernatant was discarded. The pellet was washed with 150 $\mu \mathrm{l}$ of phosphate buffered saline (PBS) and air-dried overnight. Thereafter, $100 \mu \mathrm{l}$ of dimethyl sulfoxide was added to each well and the plate agitated on an orbital shaker for $1 \mathrm{~h}$. The optical density of the wells was measured at $570 \mathrm{~nm}\left(\mathrm{OD}_{570}\right)$ with a reference wavelength of $630 \mathrm{~nm}$ using an ELx800 Universal Microplate Reader. Percentage cell inhibition was determined using the formula:
Polarization-optical transmitted light differential interference contrast microscopy (PlasDIC) examination of cell cultures Cells $(250 \mu \mathrm{l} /$ well $)$ were seeded into 24 -well cell culture plates and exposed to 2-fold serial dilutions of Pectinex (7.42-950 PGU/ml). Mitomycin C $(10 \mu \mathrm{g} / \mathrm{ml})$ served as the positive control and untreated cells were used as negative controls. The final volume in each well was titrated to $500 \mu \mathrm{l}$ using culture medium. Following a $24 \mathrm{~h}$ incubation period, cell morphology and density were observed by PlasDIC at $\times 400$ magnification. Images were captured with AxioVision camera software.

\section{Microorganisms}

S. aureus (ATCC 12600) and P. aeruginosa (ATCC 9027) were purchased from Davies Diagnostics and clinical strains were sourced from Department of Microbiology at the National Health Laboratory Services, Pretoria. Pure cultures were grown and maintained on Mueller-Hinton agar. Fresh $24 \mathrm{~h}$ sub-cultures were used for experiments.

\section{Minimum inhibitory and bactericidal concentrations of antibiotics in bacterial cultures}

The minimum inhibitory concentrations (MIC) of of the test substances were determined using a modified broth microdilution assay [21]. Wells in 96-well microtitre plates were inoculated with $100 \mu \mathrm{l}$ of bacterial suspension $\left(1 \times 10^{6} \mathrm{CFU} \mathrm{m}{ }^{-1}\right), 20 \mu \mathrm{l}$ of a serial dilution of a test agent and $80 \mu \mathrm{l}$ of Mueller-Hinton broth. Amoxicillin-clavulanate at concentrations of $0.03-4.0 \mu \mathrm{g} / \mathrm{ml}^{-1}$ and $0.125-16.0$ $\mu \mathrm{g} / \mathrm{ml}^{-1}$ was used against standard and clinical strains of $S$. aureus, respectively. Ciprofloxacin $\left(0.03-4.0 \mu \mathrm{g} / \mathrm{ml}^{-1}\right)$ was used against both strains of $P$. aeruginosa. Pectinex (7.42 $950 \mathrm{PGU} / \mathrm{ml}^{-1}$ ) was used against both bacteria. Following $24 \mathrm{~h}$ incubation at $37^{\circ} \mathrm{C}, 20 \mu \mathrm{l}$ of $0.20 \mathrm{mg} / \mathrm{ml}^{-1} p$-INT aqueous solution (Sigma-Aldrich) was added to the wells and the cultures were incubated for a further $6 \mathrm{~h}$ at room temperature. The MIC was taken as the concentration of antimicrobial in the first colourless well.

The minimum bactericidal concentration (MBC) was determined by subculture of the contents of the first two clear wells obtained in the MIC assay. Plates were incubated at $37^{\circ} \mathrm{C}$ for $24 \mathrm{~h}$. The MBC was regarded as the lowest concentration of antimicrobial agent that killed $\geq$ 99.9\% of the initial bacterial population. Checkerboard $\mathrm{MIC}$ and MBC assays were used to evaluate the effects of 8 doubling concentrations of Pectinex (7.42 to 950 PGU ml $\mathrm{m}^{-1}$ ) on the antibacterial efficacy across a range of

$$
\% \text { inhibition }=\frac{100 \times\left[\text { mean } \mathrm{OD}_{570} \text { of negative control }- \text { mean } \mathrm{OD}_{570} \text { of sample }\right]}{\text { mean } \mathrm{OD}_{570} \text { of negative control }}
$$


8 doubling concentrations of amoxicillin-clavulanate. The results were compared with those obtained by treatment with the antibiotic alone.

\section{Quantitative biofilm biomass and viability assays in bacterial cultures}

Total biofilm mass and biofilm cell viability were respectively measured using a modified crystal violet $(\mathrm{CV})$ assay of Pitts et al. [22] and a modified MTT assay of Grare et al. [20]. To assess the efficacy of the test agents during biofilm formation, bacterial suspensions $(100 \mu \mathrm{l}$ of standardized culture plus $80 \mu \mathrm{l}$ of Mueller-Hinton broth) were incubated with test agents $(20 \mu \mathrm{l})$ for 6 and $24 \mathrm{~h}$ at $37^{\circ} \mathrm{C}$. The effects were evaluated in $6 \mathrm{~h}$ and $24 \mathrm{~h}$ biofilms by challenging the biofilms with test agents for 18 and $24 \mathrm{~h}$, respectively.

To determine biofilm biomass air-dried plates were stained with $200 \mu \mathrm{l}$ of $0.1 \%$ (w/v) CV for $30 \mathrm{~min}$ at room temperature after which the plates were washed thrice to remove unabsorbed stain. Plates were air-dried overnight and the stain that was adsorbed onto the biofilm was solubilized by adding $200 \mu \mathrm{l}$ of $95 \%$ ethanol to each well (15-20 min). The OD560 $\mathrm{nm}$ of solubilised CV was measured with a microplate reader.

To determine cell viability following incubation, $20 \mu \mathrm{l}$ of MTT was added to all the wells and incubated for a further $2 \mathrm{~h}$ at $37^{\circ} \mathrm{C}$. Thereafter the plates were left to dry overnight in a dark cupboard. MTT formazan precipitate was solubilised by adding $200 \mu \mathrm{l}$ of dimethyl sulfoxide to the wells and allowing the plates to stand in the dark for $60 \mathrm{~min}$ at room temperature after which OD560 $\mathrm{nm}$ of solubilised MTT formazan was measured. Absorbance values were corrected by subtracting the mean of absorbance readings of sterile water (experiment blanks). The percentage reductions in biofilm biomass and viable bacteria were calculated as the difference in absorbance between the treatment wells and the mean absorbance of the negative (untreated) controls and expressed as a percentage of the mean absorbance of the negative controls.

\section{Electron microscopy of bacterial biofilms}

Biofilms were grown on glass coverslips placed in 6-well microtitre plates. During incubation, newly forming and preformed (24 h-old) biofilms were challenged for $24 \mathrm{~h}$ using amoxicillin-clavulanate at the MIC values (Table 1), Pectinex 118.75 PGU/ml ${ }^{-1}$, or a combination of the antibiotic with Pectinex. Positive (amoxicillin-clavulanate 32 $\mu \mathrm{g} / \mathrm{ml}^{-1}$ or ciprofloxacin $8 \mu \mathrm{g} / \mathrm{ml}^{-1}$, and pectinex 950 $\mathrm{PGU} / \mathrm{ml}^{-1}$ ) and negative (untreated) controls were included. Pectinex 118.75 PGU/ml was chosen as the highest non-toxic dose on the basis of the results of the cytotoxicity MTT assays and PlasDIC microscopy. After incubation the coverslips were rinsed three times with PBS. Biofilms adherent to the coverslips were prepared for SEM using the described method of Kim et al. [23] with modifications. Specimens were fixed in $2.5 \%$ glutaraldehyde in $0.075 \mathrm{M} \mathrm{PBS}$ for $1 \mathrm{~h}$ at room temperature. Secondary fixation was done with $0.5 \%$ aqueous osmium tetroxide for $1-2 \mathrm{~h}$ at room temperature, followed by a triple sequence of rinsing in PBS. Fixed biofilm specimens were dehydrated by transfer through increasing concentrations of ethanol $(30,50,70,90,100,100$ and $100 \%)$ for $10 \mathrm{~min}$ at each concentration. Final preparation entailed critical point drying with liquid $\mathrm{CO}_{2}$ and sputter coating with gold (Emitech K550X Sputter Coater). Biofilms were imaged by scanning electron microscopy and characterized as weak, moderately adherent or fully established as described by Smith et al. [24].

\section{Statistical analysis}

For cytotoxicity, 6 replicate experiments were performed for each cell type. Results were expressed as the percentage cell inhibition \pm the standard error of the mean (SEM). The concentration that achieved 50\% inhibition of cell growth $\left(\mathrm{IC}_{50}\right)$ was determined using ED50plus version 1.0 software and expressed as $\mathrm{IC}_{50} \pm$ SEM.

Microbiology experiments were carried out at least in triplicate and on three separate occasions. Biofilm growth (i.e. biofilm biomass and cell viability) was expressed as the percentage reduction of negative controls \pm SEM. Therefore, $0 \%$ inhibition represented growth in untreated cultures. In treated cultures, a value $>0 \%$ indicated positive inhibition (i.e. reduced growth) and a value $<0 \%$ indicated negative inhibition (i.e. increased growth). Data were analyzed for statistical significance using GraphPad Prism version 5.0 software. Analysis of

Table 1 MIC and MBC of antibiotics alone, and in antibiotic-Pectinex combinations (checkerboard), against S. aureus and $P$. aeruginosa

\begin{tabular}{|c|c|c|c|c|}
\hline & \multicolumn{2}{|c|}{ Amoxicillin-clavulanate $(\mu \mathrm{g} / \mathrm{ml})$} & \multicolumn{2}{|l|}{ Ciprofloxacin $(\mu \mathrm{g} / \mathrm{ml})$} \\
\hline & S. aureus ATCC & S. aureus clinical strain & P. aeruginosa ATCC & P. aeruginosa clinical strain \\
\hline $\mathrm{MIC}$ & $0.42( \pm 0.08)$ & $2.0( \pm 0.0)$ & $0.13( \pm 0.0)$ & $1.0( \pm 0.0)$ \\
\hline $\mathrm{MBC}$ & $0.50( \pm 0.0)$ & $2.0( \pm 0.0)$ & $0.33( \pm 0.08)$ & $1.67( \pm 0.33)$ \\
\hline Checkerboard MIC & $0.42( \pm 0.04)$ & $2.56( \pm 0.38)$ & $0.12( \pm 0.01)$ & $1.89( \pm 0.11)$ \\
\hline Checkerboard MBC & $0.56( \pm 0.09)$ & $2.56( \pm 0.38)$ & $0.32( \pm 0.05)$ & $3.22( \pm 0.40)$ \\
\hline
\end{tabular}

[Results expressed as mean \pm SEM] 
variables was carried out using Kruskal-Wallis one-way analysis of variance with Dunn's multiple-comparison procedure. Comparisons were made between the different concentrations of Pectinex and the experiment controls; a $p$-value $\leq 0.05$ was considered to be statistically significant.

\section{Results and discussion}

\section{Effect of Pectinex on cell cultures}

Enzymes are generally regarded as non-toxic and as a result only a few in vitro studies examining their cytotoxicity are found in the literature [13]. However, allergic reactions to inhaled aerosolized enzymes and contact irritation of the skin and eyes are known to be associated with either occupational or accidental exposure [25]. In view of the growing awareness of occupational and consumer safety associated with industrial enzymes, this study assessed the cytotoxicity of Pectinex Ultra SP-L, widely used in the food and beverage industry.

HeLa cell growth was significantly $(\mathrm{p} \leq 0.05)$ inhibited by Pectinex concentrations $\geq 237.5 \mathrm{PGU} / \mathrm{ml}$ (Figure 1A), and the effect was comparable to mitomycin $C$ (positive control) which inhibited cell survival by $99.0 \%( \pm 1.6)$. The $\mathrm{IC}_{50}$ of Pectinex in HeLa cell cultures was 193.9 ( \pm 22.2$)$ PGU/ml. Pectinex $950 \mathrm{PGU} / \mathrm{ml}$ caused a significant $(\mathrm{p} \leq 0.05)$ decrease in the viability of both lymphocytes (Figure 1B) and neutrophils (Figure 1C). Previously, it has been reported that stimulation of blood cells with fMLP could lead to an increase in cell survival [26]. However, in this study no significant difference between the survival in fMLP-stimulated and non-stimulated cells was noted. The $\mathrm{IC}_{50}$ of Pectinex was 383.4 $( \pm 81.5)$ and 629.6 $( \pm 62.8) \mathrm{PGU} / \mathrm{ml}$ in fMLP-stimulated and non-stimulated lymphocytes, respectively, and $245.9( \pm 9.4)$ and 529.7 $( \pm 40.7) \mathrm{PGU} / \mathrm{ml}$ in fMLP-stimulated and non-stimulated neutrophils, respectively. There was no statistically significant difference in the $\mathrm{IC}_{50}$ between any of the cell types.

Examination by PlasDIC microscopy revealed morphological features characteristic of apoptosis and necrosis in all cell cultures (Figure 2). These included shrunken rounded cells, cell membrane blebs, apoptotic bodies, cytoplasmic vacuoles, cell clumping and cell debris [27]. Vacuolization and clumping (aggregation of cells and debris) were present in HeLa cells (Figure 2B) and lymphocytes (Figure 2C), respectively. In all cell cultures, Pectinex caused a dose-dependent decrease in the number of normal cell and total cell counts per microscopic field. HeLa cells (Figure 2B) and neutrophils (Figure $2 \mathrm{~F}$ ) showed almost no evidence of morphological changes at concentrations of $7.42-29.69$ PGU/ml and 7.42 - 118.57 PGU/ml, respectively. Conversely, lymphocytes exhibited evidence of cell death at all concentrations.
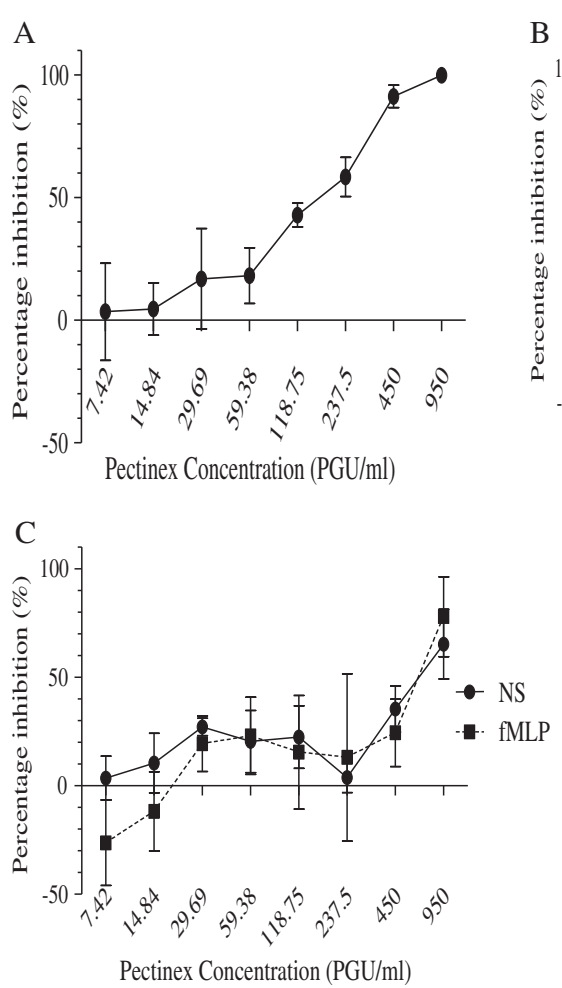

B

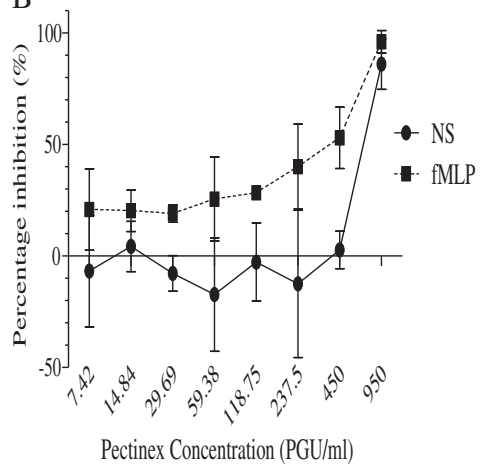

Figure 1 Percentage inhibition \pm SEM after Pectinex challenge in HeLa cells $[A]$, non-stimulated (NS) and fMLP-stimulated lymphocytes $[B]$ and neutrophils $[C]$. 


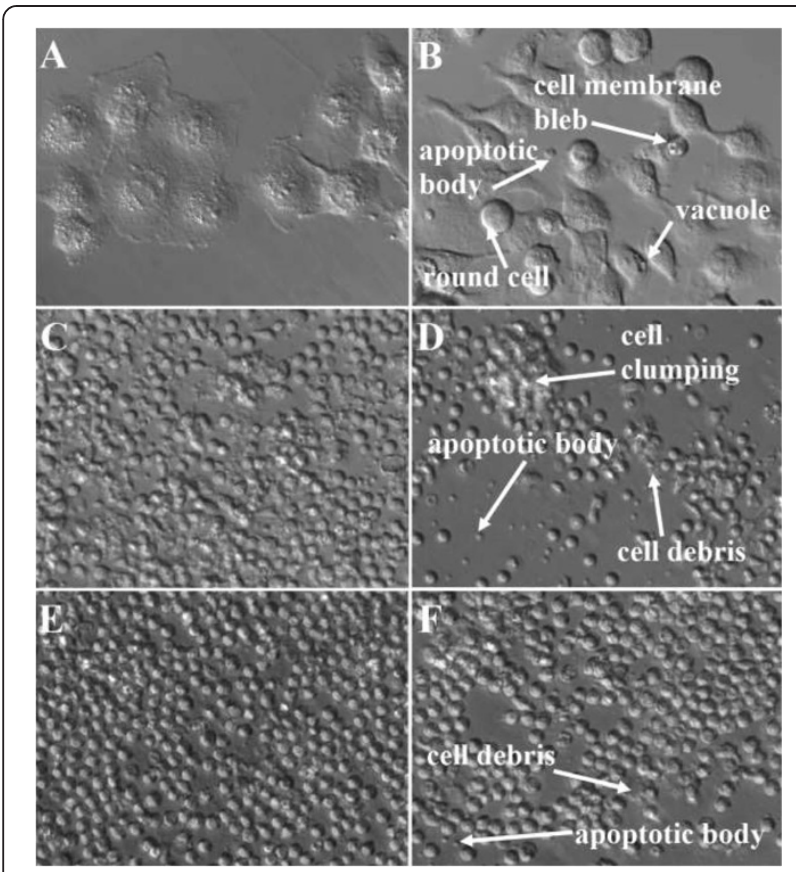

Figure 2 PlasDIC microscopy images ( $x 400$ magnification) after $24 \mathrm{~h}$ treatment with Pectinex 237.5 PGU/ml and in untreated controls. A: HeLa cell control; B: HeLa cells treated; C: Lymphocyte control; D: Lymphocytes treated; E: Neutrophil control; F: Neutrophils treated.

Polygalacturonase activity in Pectinex is known to catalyze the degradation of polygalacturonan in the cell walls of plants by hydrolysis of $\alpha-(1-4)$ glycosidic bonds that link galacturonic acid residues [28]. Studies have also reported the presence of other enzyme activity including $\beta$-galactosidase and fructosyltransferase $[28,29]$. In addition, there is possible protease and lipase activity in Aspergillus-derived enzymes [11]. In this study, the cytotoxic property of Pectinex in cell cultures was unexpected. In contrast to plant cells, mammalian cell membranes comprise phospholipids, proteins and oligosaccharides, and are susceptible to damage by proteases [30,31]. Toxicity by a non-proteolytic enzyme has been reported in a study where intraperitoneal injection of a crude fungal (Gliomastix murorum) enzyme extract into Swiss albino mice was found to be toxic to the liver, kidney and bone marrow [32]. This fungal extract is widely used in the food and drug industries and is known to contain an enzyme, alpha mannosidase.

From the microscopy results, it would appear that apoptosis may have been triggered as a stress response to cell membrane damage [27]. A possible mechanism for Pectinex cytotoxicity may be due to enzymatic activity on the cell membrane. Mammalian cells are covered by a carbohydrate coat (glycocalix) of membrane-bound oligosaccharides (glycolipids and glycoproteins) that are essential to the survival of cells $[31,33]$. Pectinex may have caused cell death by degrading the oligosaccharides thereby disrupting the function and/or integrity of the cell membrane. It is also possible that proteolytic activity may have been involved [11].

\section{Effect of Pectinex, amoxicillin-clavulanate and ciprofloxacin on bacteria}

In a search for new ways to overcome antimicrobial resistance, the effect of Pectinex and antibiotics was studied on planktonic and biofilm cultures of standard and clinical strains of $S$. aureus and $P$. aeruginosa. These bacteria have proven ability to form biofilms under test conditions and their importance as clinical pathogens is clear $[34,35]$. Pectinex $\left(7.42-950 \mathrm{PGU} / \mathrm{ml}^{-1}\right)$ did not inhibit their growth in either standard or clinical cultures and therefore MIC values were not achieved. This result was consistent with the findings of Johansen et al. [12] who found that Pectinex $\left(0.18-1800 \mathrm{PGU} / \mathrm{ml}^{-1}\right)$ was not bactericidal. Bacterial cultures were susceptible to amoxicillin-clavulanate and ciprofloxacin (Table 1). The MIC values were within published ranges for the respective antibiotics against $S$. aureus (amoxicillin-clavulanate, $1.0-16.0 \mu \mathrm{g} / \mathrm{ml}$ ) and $P$. aeruginosa (ciprofloxacin, $0.25-1.0 \mu \mathrm{g} / \mathrm{ml}$ ) [36,37]. Contrary to expectations, Pectinex did not augment the bactericidal effect of either amoxicillin-clavulanate or ciprofloxacin. Instead, Pectinexantibiotic combinations were associated with decreased susceptibility to the antibiotics in clinical cultures, as indicated by an increase in the MIC and MBC (Table 1). No change in the susceptibility to antibiotics occurred in standard cultures. In an animal model experiment, Mecikoglu et al. [38] showed that the proteolytic enzyme, serratiopeptidase, enhanced the efficacy of antibiotics in the treatment of an infected knee implant. A number of in vitro studies using various different antibiotic and enzyme combinations have also demonstrated increased antibiotic susceptibility in bacterial cultures [7,38,39]. Alkawash et al. [40] showed that alginate lyase increased the susceptibility of $P$. aeruginosa to gentamicin and alginate lyase in $P$. aeruginosa cultures. In contrast, Diaz et al. [41] found that the susceptibility of $P$. aeruginosa to gentamicin decreased despite treatment with alginate lyase. This suggests that different outcomes may occur even where the same combination of agents is used.

This study found that low concentrations of Pectinex $\left(\leq 118.57 \mathrm{PGU} / \mathrm{ml}^{-1}\right)$ promoted biofilm adhesion, growth and cell viability in young $(0-6 \mathrm{~h})$ cultures of $S$. aureus and $P$. aeruginosa. At higher concentrations there was a mixed response of either inhibition or no effect. P. aeruginosa ATCC 9027 was found to be most susceptible to the antibiofilm actions of Pectinex (Figure 3A). Antibiotic concentrations $\geq$ MIC significantly reduced biofilm formation and cell viability in young bacterial 


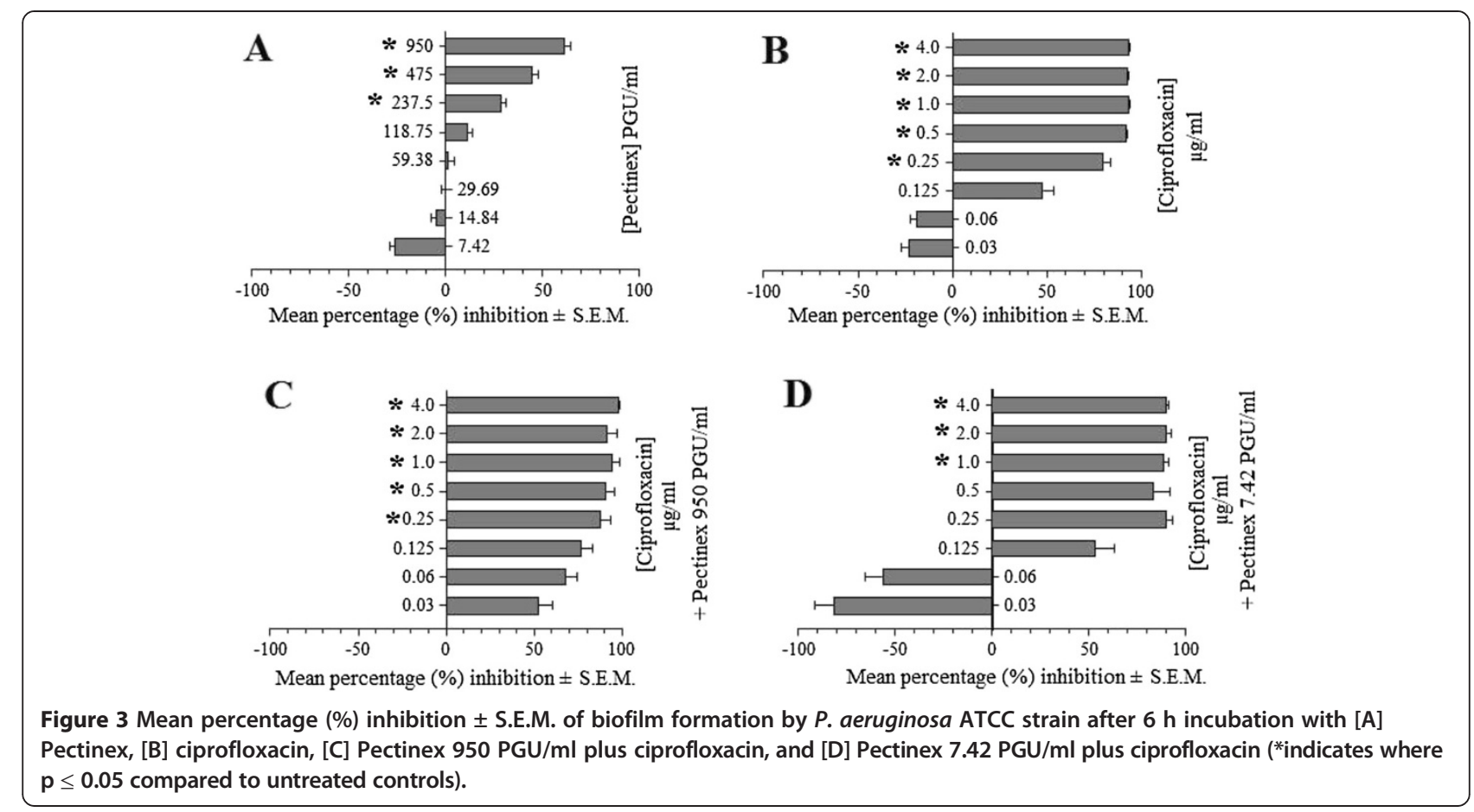

cultures. Antibiotic concentrations below their respective MIC's were associated with increased adhesion (Figure 3B) and cell viability. However, the findings were not statistically significant. With concurrent administration of Pectinex, biofilm biomasses and cell viabilities were statistically different $(\mathrm{p} \leq 0.05)$ to untreated controls. However, no significant $(\mathrm{p}>0.05)$ differences occurred between combined regimens and treatment with antibiotics alone (Figure $3 \mathrm{C}-\mathrm{D}$ ). A similar pattern of responses was observed in all other tested strains with the main difference being a variation in the magnitude of the responses. Bacterial resistance to antibiotics, Pectinex and their combination increased following periods of incubation over $6 \mathrm{~h}$ and was found to be highest in $24 \mathrm{~h}$-old preformed biofilms. A similar pattern was observed in all other tested strains, with variations in the magnitude of the responses. These findings may be explained by the fact that naturally resistant bacteria survive the initial antibiotic attack and thereafter multiply and repopulate the colonies (planktonic and biofilm) with a selection of antibiotic resistant bacteria [42]. Interestingly, Pectinex 950 $\mathrm{PGU} / \mathrm{ml}^{-1}$ plus amoxicillin-clavulanate $2.0 \mu \mathrm{g} / \mathrm{ml}^{-1}$ inhibited S. aureus ATCC 12600 adhesion to a greater extent than the untreated control, although neither agent on its own produced a statistically significant effect. However, this was an isolated finding and the magnitude of change did not amount to either an additive or synergistic interaction.

The electron microscopy images of the biofilms showed that treatment with Pectinex compared to the untreated controls was associated with an increase in the number of adherent bacteria in standard cultures of $S$. aureus and $P$. aeruginosa. However, the precise responses were found to vary between the species (and strains). S. aureus biofilms from mature cultures $(24-48 \mathrm{~h})$ were more resistant to antimicrobial agents than the fresh $(0-24$ h) biofilms whereas the converse was true for P. aeruginosa biofilms. These findings were consistent with those of Leroy et al. [43] who found that the activity of low concentrations of Pectinex, and several other enzymes (including $\alpha$-amylase, and cellulase), significantly increased bacterial adhesion in 3 h-old cultures of Pseudoalteromonas species, whereas higher concentrations reduced adhesion. From the evidence possible resistance mechanisms which the bacteria may have employed against Pectinex include the expression of resistance genes, the stimulation of metabolism and growth by fungal growth factors and the utilization of components of Pectinex as a source of nutrients $[43,44]$. In addition, the growth rate of the bacteria may have been enhanced, or the effectiveness of the enzyme diminished, by the availability of nutrientrich growth media $[45,46]$. The findings do not support previous research by Johansen et al. [11] and Chaignon et al. [12], which showed Pectinex to be effective against biofilms of $P$. aeruginosa and $S$. aureus. Johansen et al. [11] investigated the use of Pectinex for its potential as an industrial cleaning agent and demonstrated that Pectinex concentrations as low as $0.18-1.8 \mathrm{PGU} / \mathrm{ml}$ effectively removed biofilms of $S$. aureus. S. epidermidis, $P$. aeruginosa and $P$. fluorescens. 


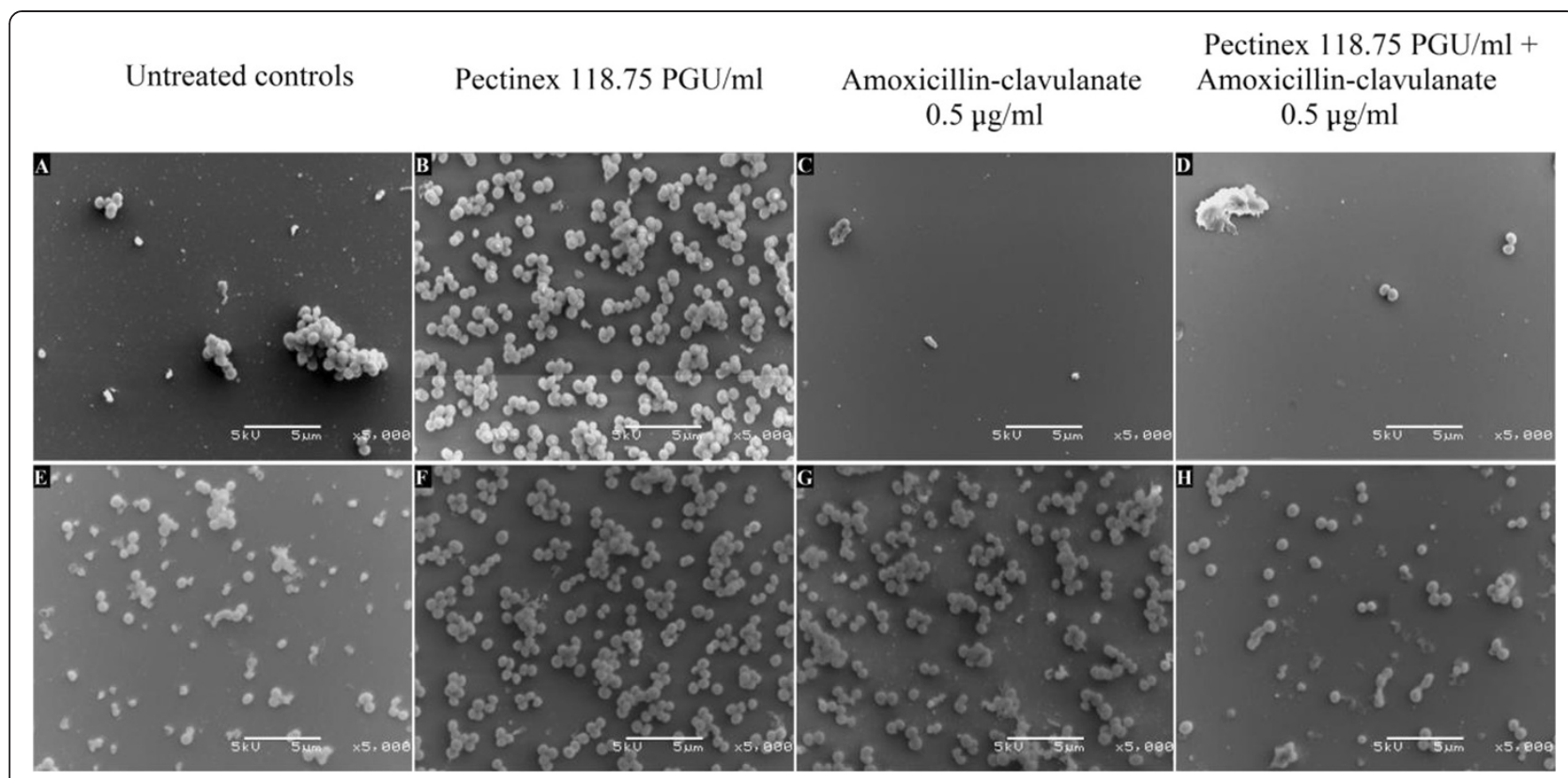

Figure 4 Scanning electron microscopy (x5000 magnification) of S. aureus ATCC after incubation from $0-24$ h (A - D) and $24-48 \mathrm{~h}$ $(E-H)$.

In this study, electron microscopy images of biofilms showed monolayers of few adherent cells in the untreated controls of both bacteria. These weak biofilms may have been due to the formation of loose biofilm in the nutrient-rich culture medium. An earlier study has shown that high nutrient levels (e.g. succinate, glutamate or glucose) caused up to $80 \%$ reduction in biofilm biomass [47]. In addition, loss of biofilm cells may also have occurred during the fixation and rinsing stages of specimen preparation [23]. Nevertheless compared to the untreated controls treatment with Pectinex was associated with an increase in the number of adherent bacteria, in standard cultures of $S$. aureus and $P$. aeruginosa cultures. The responses were found to vary between the species (and strains).

In S. aureus ATCC 12600 cultures, biofilms grew in the presence of Pectinex (Figure $4 \mathrm{~B}$ and $4 \mathrm{~F}$ ), older biofilms $(24-48 \mathrm{~h})$ were more resistant than fresh $(0-$ $24 \mathrm{~h}$ ) biofilms to the effect of the amoxicillin-clavulanate alone (Figure $4 \mathrm{C}$ and $4 \mathrm{G}$ ) as well as when combined with Pectinex (Figure 4D and 4H). A similar trend was observed with biofilms from clinical cultures of $S$. aureus. Exceptionally weak biofilms were produced by both strains of $P$. aeruginosa.

\section{Conclusion}

This study is the first to assess the cytotoxic effects of Pectinex Ultra SP-L in human cell cultures. The enzyme was found to be toxic to HeLa cells, lymphocytes and neutrophils. Apoptosis appeared to predominate following exposure to the enzyme. This suggests that the cell types are equally susceptible to Pectinex inhibition. The mechanism by which Pectinex exerted its cytotoxic action requires further investigation. Although industrial food enzymes are regarded as safe, the study supports the notion that caution should be taken during nonconventional use and exposure to these enzymes.

Pectinex was not effective in the treatment of planktonic or biofilm forms of $S$. aureus and P. aeruginosa. The enzyme failed to prevent the formation of new biofilm or to reduce biomass and cell viability in preformed biofilms. Rather, low concentrations of Pectinex ( $\leq 118.75$ PGU/ml) were associated with increased biofilm biomass and the number of viable bacteria. Pectinex significantly reduced the antibacterial and antibiofilm actions of amoxicillinclavulanate and ciprofloxacin against $S$. aureus and P. aeruginosa, respectively. Pectinex was thus found to be an unsuitable candidate for management of either planktonic or biofilm phenotypes of S. aureus or P. aeruginosa.

\section{Competing interests}

The authors declare that they have no competing interests.

\section{Authors' contributions}

IO: Carried out the research, wrote the first draft. OG: Co-supervised research, input into manuscript. GJ: Assisted with cytotoxicity and antimicrobial analyses. VS: Supervised research, analysis of data, assisted with manuscript write up. All authors have read the final manuscript and approved submission.

\section{Acknowledgements}

The authors are grateful for the funding received from the School of Medicine, Faculty of Health Sciences, University of Pretoria, and the Department of Pharmacology, to carry out this research.

Received: 19 May 2014 Accepted: 23 September 2014

Published online: 02 October 2014 


\section{References}

1. Zucca M, Savoia D: The post-antibiotic era: promising developments in the therapy of infectious diseases. Int J Biomed Sci 2010, 6(2):77-86.

2. Arias CA, Murray BE: Antibiotic-resistant bugs in the 21st century - a clinical super-challenge. N Eng/ J Med 2009, 360(5):439-443.

3. Public Policy IDSA: The $10 \times$ ' 20 Initiative: Pursuing a global commitment to develop 10 new antibacterial drugs by 2020. Clin Infect Dis 2010, 50(8):1081-1083.

4. Kaplan JB: Biofilm dispersal: mechanisms, clinical implications, and potential therapeutic uses. J Dent Res 2010, 89(3):205-219.

5. Fux CA, Wilson S, Stoodley P: Detachment characteristics and oxacillin resistance of Staphyloccocus aureus biofilm emboli in an in vitro catheter infection model. J Bacteriol 2004, 186(14):4486-4491.

6. Davies DG: Understanding biofilm resistance to antibacterial agents. Nat Rev Drug Discov 2003, 114(2):114-122.

7. Nickel JC, Ruseska I, Wright JB, Costerton JW: Tobramycin resistance of Pseudomonas aeruginosa cells growing as a biofilm on urinary catheter material. Antimicrob Agents Chemother 1985, 27(4):619-624.

8. Xavier JB, Picioreanu C, Rani SA, Van Loosdrecht MCM, Stewart PS: Biofilmcontrol strategies based on enzymic disruption of the extracellular polymeric substance matrix - a modelling study. Microbiology 2005, 151(12):3817-3832.

9. Van Beilen JB, Li Z: Enzyme technology: an overview. Curr Opin Biotechnol 2002, 13(4):338-344.

10. Ward OP, Qin WM, Dhanjoon J, Ye J, Singh A: Physiology and biotechnology of Aspergillus. Adv Appl Microbiol 2006, 58:1-75.

11. Johansen C, Falholt P, Gram L: Enzymatic removal and disinfection of bacterial biofilms. Appl Env Microbiol 1997, 63(9):3724-3728.

12. Chaignon P, Sadovskaya I, Ragunath C, Ramasubbu N, Kaplan JB, Jabbouri S: Susceptibility of staphylococcal biofilms to enzymatic treatments depends on their chemical composition. App/ Microbiol Biotechnol 2007, 75(1):125-132.

13. Donelli G, Francolini I, Romoli D, Guaglianone E, Piozzi A, Ragunath C, Kaplan JB: Synergistic activity of dispersin B and cefamandole nafate in inhibition of staphylococcal biofilm growth on polyurethanes. Antimicrob Agents Chemother 2007, 51(8):2733-2740.

14. Basketter D, Berg N, Broekhuizen C, Fieldsend M, Kirkwood S, Kluin C, Mathieu S, Rodriguez C: Enzymes in cleaning products: an overview of toxicological properties and risk assessment/management. Regul Toxicol Pharmacol 2012, 64(1):117-123.

15. Spök A: Safety regulations of food enzymes. Food Technol Biotechnol 2006, 44(2):197-209.

16. Pariza MW, Johnson EA: Evaluating the safety of microbial enzyme preparations used in food processing: update for a new century. Regul Toxicol Pharmacol 2001, 33(2):173-186.

17. Ventola CL: Off-label drug information: regulation, distribution, evaluation, and related controversies. Pharm Ther 2009, 34(8):428-440.

18. Schrek R: A method for counting the viable cells in normal and in malignant cell suspensions. Am J Cancer 1936, 28(2):389-392.

19. Pretlow TG, Luberoff DE: A new method for separating lymphocytes and granulocytes from human peripheral blood using programmed gradient sedimentation in an isokinetic gradient. Immunology 1973, 24(1):85-92.

20. Grare M, Fontanay S, Cornil C, Finance C, Duval RE: Tetrazolium salts for MIC determination in microplates: Why? Which salt to select? How? J Microbiol Methods 2008, 75(1):156-159.

21. Eloff JN: A sensitive and quick microplate method to determine the minimal inhibitory concentration of plant extracts for bacteria. Planta Med 1998, 64(8):711-713.

22. Pitts B, Hamilton MA, Zelver N, Stewart PS: A microtiter-plate screening method for biofilm disinfection and removal. J Microbiol Methods 2003, 54(2):269-276

23. Kim JE, Choi NH, Kang SC: Anti-listerial properties of garlic shoot juice at growth and morphology of Listeria monocytogenes. Food Control 2007, 18:1198-1203.

24. Smith K, Perez A, Ramage G, Lappin D, Gemmell CG, Lang S: Biofilm formation by Scottish clinical isolates of Staphylococcus aureus. J Med Microbiol 2008, 57(8):1018-1023.

25. Green BJ, Beezhold DH: Industrial fungal enzymes: an occupational allergen perspective. J Allergy 2011, 2011:11 pages.
26. Orie NN, Zidek W, Tepel M: Chemoattractant- and mitomycin-induced generation of reactive oxygen species in human lymphocytes: The role of calcium. Exp Physiol 1999, 84(3):515-520.

27. Elmore S: Apoptosis: a review of programmed cell death. Toxicol Pathol 2007, 35(4):495-516.

28. Cho SW, Lee S, Shin W: The x-ray structure of Aspergillus aculeatus polygalacturonase and a modeled structure of the polygalacturonaseoctagalacturonate complex. J Mol Biol 2001, 314(4):863-878.

29. Aslan Y, Tanriseven A: Immobilization of Pectinex Ultra SP-L to produce galactooligosaccharides. J Mol Catal B: Enzym 2007, 45:73-77.

30. Montilla A, Corzo N, Olani A, Jimeno ML: Identification of oligosaccharides formed during stachyose hydrolysis by Pectinex Ultra SP-L. J Agric Food Chem 2009, 57(11):5007-5013.

31. Singer SJ, Nicolson GL: The structure and chemistry of mammalian cell membranes. Am J Pathol 1971, 65(2):427-437.

32. Aritajat $\mathrm{S}$, Saenphet $\mathrm{K}$, Srikalayanukul C: The toxicity of a crude enzyme extract from Gliomastix murorum in Swiss Albino mice. Southeast Asian Trop Med Public Heal 2005, 36(Suppl 4):242-245.

33. Varki A: Biological roles of oligosaccharides: all of the theories are correct. Glycobiology 1993, 3(2):97-130.

34. Fux CA, Stoodley P, Hall-Stoodley L, Costerton JW: Bacterial biofilms: a diagnostic and therapeutic challenge. Expert Rev Anti Infect Ther 2003, 1(4):667-683.

35. Costerton JW, Stewart PS, Greenberg EP: Bacterial biofilms: A common cause of persistent infections. Science 1999, 284(5418):1318-1322.

36. Hoogkamp-Korstanje JAA: In-vitro activities of ciprofloxacin, levofloxacin lomefloxacin, ofloxacin, pefloxacin, sparfloxacin and trovafloxacin against gram-positive and gram-negative pathogens from respiratory tract infections. J Antimicrob Chemother 1997, 40(3):427-431.

37. Prieto J, Aguilar L, Giménez MJ, Toro D, Gómez-Lus ML, Dal-Ré R, Balcabao IP: In vitro activities of co-amoxiclav at concentrations achieved in human serum against the resistant subpopulation of heteroresistant Staphylococcus aureus: a controlled study with vancomycin. Antimicrob Agents Chemother 1998, 42(7):1574-1577.

38. Mecikoglu M, Saygi B, Yildirim Y, Karadag-Saygi E, Ramadan SS, Esemenli T: The effect of proteolytic enzyme serratiopeptidase in the treatment of experimental implant-related infection. J Bone Jt Surg Am 2006, 88(6):1208-1214.

39. Nemoto K, Hirota K, Ono T, Murakami K, Murakami K, Nagao D, Miyake Y: Effect of Varidase (Streptokinase) on biofilm formed by Staphylococcus aureus. Chemotherapy 2000, 46(2):111-115.

40. Alkawash MA, Soothill JS, Schiller NL: Alginate lyase enhances antibiotic killing of mucoid Pseudomonas aeruginosa in biofilms. APMIS 2006, 114(2):131-138.

41. Diaz E, Haaf H, Lai A, Yadana J: Role of alginate in gentamicin antibiotic susceptibility during the early stages of Pseudomonas aeruginosa PAO1 biofilm establishment. JEMI 2011, 15(4):71-78.

42. Singh R, Ray P, Das A, Sharma M: Role of persisters and small-colony variants in antibiotic resistance of planktonic and biofilm-associated Staphylococcus aureus: an in vitro study. J Med Microbio/ 2009, 58(8):1067-1073.

43. Leroy C, Delbarre C, Ghillebaert F, Compere C, Combes D: Effects of commercial enzymes on the adhesion of a marine biofilm-forming bacterium. Biofouling 2008, 24(1):11-22.

44. Campos-Montiel RG, Viniegra-Gonzales G: Microbial bioassay of fungal compounds that stimulate the growth of a consortium of anaerobic cellulolytic bacteria. Biotechnol Tech 1995, 9(1):65-68.

45. Nazir $R$, Warmink JA, Boersma $H$, van Elsas JD: Mechanisms that promote bacterial fitness in fungal-affected soil microhabitats. FEMS Microbiol Ecol 2010, 71(2):169-185.

46. Augustin M, Ali-Vehmas T, Atroshi F: Assessment of enzymatic cleaning agents and disinfectants against bacterial biofilms. J Pharm Pharm Sci 2004, 7(1):55-64.

47. Sauer K, Cullen MC, Rickard AH, Zeef LAH, Davies DG, Gilbert P: Characterization of nutrient-induced dispersion in Pseudomonas aeruginosa PAO1 biofilm. J Bacteriol 2004, 186(21):7312-7326.

doi:10.1186/s12866-014-0251-1

Cite this article as: Olwoch et al:: The effects of the natural enzyme, Pectinex Ultra SP-L, on human cell cultures and bacterial biofilms in vitro. BMC Microbiology 2014 14:251. 